\title{
E.d.i.t.o.r.i.a.l.
}

\section{Internacionalização e Produção Científica}

Internacionalización y Producción Científica

Internationalization and Scientific Production

\author{
Pedrinho Guareschi \\ ORCID: https://orcid.org/0000-0003-0875-5865 \\ Docente Convidado da Universidade Federal do Rio Grande do Sul
}

Cristiane Davina Redin Freitas

ORCID: https://orcid.org/0000-0002-1288-2712

Docente do Departamento de Psicologia da UNISC

A internacionalização vêm sendo tema de debates atuais e uma das exigências mais recentes das agências de fomento à pesquisa tanto no que se refere à cooperação entre universidades, quanto às publicações realizadas por autores de diferentes nacionalidades. Obviamente, existem diferenças entre as diversas áreas do conhecimento em relação a essa demanda, mas de forma geral boas publicações são aquelas em que se pode contar com nomes internacionais. Essa característica, contudo, não basta para que uma produção científica seja considerada amplamente divulgada; precisa antes ser submetida a no mínimo três exigências de internacionalização, quais sejam: a difusão, a colaboração entre pares e o impacto. De qualquer modo, a internacionalização da produção científica se destaca como aspecto fundamental para a difusão de qualquer pesquisa, além de ser uma preocupação importante para cientistas de diversos países. Há mais de uma década Fiorin (2007, p.264) já lembrava que: “o mérito da produção cientifica (...) é o grau de sua internacionalização. É a inserção global que indica a participação de um país na produção científica mundial”.

Pesquisadores brasileiros vêm demonstrando uma crescente atenção à questão da internacionalização. Em 2005, a produção cientifica brasileira foi 1,8\% dos artigos publicados em periódicos indexados pelo ISI (Institute for Scientific Information). Seu número saltou de $13.313 \mathrm{em}$ 2004 para 15.777 em 2005. O Brasil manteve a 17. ${ }^{a}$ posição no ranking da produção científica dos diferentes países. Em 2014 a produção científica brasileira registrou altos índices de crescimento, pois o Brasil alcançou a $13^{\mathrm{a}}$ posição do ranking mundial de produção científica. Neste mesmo ano, o país registrou um volume de 507.424 artigos de circulação nacional (publicados em periódicos brasileiros) e 576.651 artigos de circulação internacional (veiculados em periódicos estrangeiros), o que corresponde a 2,7\% dos artigos publicados no mundo. (Santin, Vanz, \& Stumpf, 2016).

Os índices apresentados demonstram que o Brasil tem se inserido no meio científico internacional de maneira progressiva nos últimos anos. Esse aspecto representa o esforço dos pesquisadores brasileiros em sistematizar e internacionalizar suas produções científicas, da mesma maneira que os programas de pós-graduação têm se empenhado em construir parcerias com Universidades de outros países numa ação continua de internacionalização. A respeito disso, a colaboração e a difusão da produção científica entram como critérios importantes de avaliação da Capes aos programas de pós-graduação. A internacionalização das pesquisas brasileiras foi um dos 
temas da Estratégia Nacional de Ciência, Tecnologia e Inovação do período 2012-2015 que entre as suas discussões, colocou como pauta quais temáticas de pesquisa poderiam elevar a competitividade e inserção internacional do país, no referente aos aspectos que têm a ver com a formação e com o intercâmbio de profissionais e com um maior fortalecimento da colaboração internacional. (Brasil, 2015).

Permanecem, contudo, diversas questões pendentes em relação à produção científica brasileira no quesito internacionalização. Um exemplo é o fato apontado por Santin, Vanz e Stumpf (2016) quanto aos estudos realizados por pesquisadores de países desenvolvidos que têm forte difusão internacional e são considerados de grande valor para a ciência global, o que não ocorre da mesma maneira com as produções de países periféricos, entre os quais está o Brasil. As pesquisas realizadas nesses países precisam ultrapassar barreiras linguísticas e culturais para serem reconhecidos internacionalmente. Em relação ao caso brasileiro, Fiorin em 2007 já mostrava que grande parte de nossa produção científica era veiculada por revistas nacionais, voltadas exclusivamente ao público brasileiro, devido à utilização exclusiva da língua portuguesa na edição de seus periódicos. Além disso, a maioria das temáticas abordadas era de interesse local, ou mesmo regional, o que as tornavam menos apreciadas em termos globais. Na tentativa de superar esses obstáculos, a produção conjunta com estudiosos de países desenvolvidos tem sido uma busca intensa dos pesquisadores brasileiros para que suas produções tenham maior alcance e visibilidade.

Como lembramos acima, alguns critérios são discutidos e apontados como importantes para a avaliação da internacionalização da produção científica. O primeiro critério é o da difusão, que se caracteriza principalmente pela veiculação das pesquisas em periódicos internacionais, pela indexação dos periódicos nacionais em bases de dados internacionais e pelo uso do inglês como preferência de idioma nas publicações. Publicar em periódicos internacionais em termos de difusão, significa dimensionar a proporção de artigos publicados em periódicos estrangeiros em relação ao total de artigos de um país ou instituição. Publicar estudos em periódicos de outros países favorece a divulgação da produção científica brasileira, particularmente quando se trata de periódicos com reconhecimento mundial e ampla circulação internacional. Uma questão importante, contudo, se interpõe: como conquistar espaço em periódicos de tamanho alcance? Uma saída poderia ser abordar temáticas de amplo interesse. Mas o que precisa ser lido necessariamente em todo o mundo? Uma possível resposta foi a sugerida por Fiorini (2007, p.270): "a questão de fundo não é a de discutir se a produção cientifica apresentada em bases de dados internacionais é ou não representativa do que se faz no país, mas a de estabelecer o que é relevante e como isso deve circular". Por outro lado, aqui se coloca um ponto estratégico em relação à situação brasileira, sobre a qual os pesquisadores deveriam se perguntar: quais problemas encontrados em nosso país poderiam chamar a atenção das publicações internacionais? Existem, sem dúvida, problemáticas que devido às nossas peculiaridades deveriam fazer parte do espectro dos problemas de interesse internacional e mundial: no clamor das nações deve ressoar uma voz que pode e deve ser nossa.

Outro aspecto importante em termos de difusão é a indexação de periódicos nacionais em bases de dados internacionais. A indexação proporciona grande visibilidade no cenário internacional e torna-se um fator importante de reconhecimento de um periódico nacional. A escolha do idioma em que o estudo será redigido também vai interferir na amplitude da circulação das produções científicas. Atualmente, o inglês é considerado a língua referência da ciência mundial e, por isso, influencia enormemente na visibilidade em termos internacionais. O uso do inglês torna-se fundamental em dois aspectos: tanto nos artigos publicados em periódicos estrangeiros, como nos publicados em periódicos brasileiros que pretendem obter alcance internacional.

Como segundo critério destacamos a colaboração internacional estabelecida entre instituições, docentes e pesquisadores. Essa associação aparece em projetos de pesquisa e produções 
conjuntas que, quando publicadas, geralmente são mais citadas e, consequentemente, têm maior impacto. Esse aspecto amplia a difusão dos resultados das pesquisas em periódicos internacionais, além de dar o enfoque internacional aos periódicos brasileiros.

Como último critério abordamos a questão do impacto, que se caracteriza pelo uso da informação divulgada em outras pesquisas, através do número de citações recebidas que demonstram o desempenho da produção científica. Alcançar impacto internacional significa desenvolver estudos que interessem ao conhecimento global a partir da divulgação dos resultados e das citações recebidas em publicações internacionais. O número de citações de um autor/estudo é o maior indicador do impacto que a produção pode obter. Esse fator demonstra o reconhecimento, a qualidade do estudo e a influência do pesquisador. Se a citação é realizada por autores da comunidade internacional, maior ainda pode ser considerado o impacto e a visibilidade do artigo. Do mesmo modo, se a citação é recebida por pesquisadores estrangeiros com temáticas de pesquisa afins, pode estar aberto o campo de uma nova cooperação internacional.

Por fim, a internacionalização não é apenas uma exigência para pesquisadores, Universidades e programas de pós-graduação, mas uma questão de justiça. Esperamos que ela também sirva, para que muitas vozes existentes em diferentes regiões, principalmente as mais pobres e periféricas, possam ser ouvidas por pesquisadores de países centrais e dominantes. Uma verdadeira democracia exige que todas as possíveis contribuições sejam incorporadas ao coro dos que refletem e investigam os grandes e urgentes problemas da humanidade.

\section{Referências}

Brasil. (2012). Estratégia Nacional de Ciência, Tecnologia e Inovação 2012-2015. Ministério da Ciência, Tecnologia e Inovação, Brasília. Recuperado de http://livroaberto.ibict.br/docs/218981.pdf

Fiorin, J. L. (2007). Internacionalização da produção científica: a publicação de trabalhos de Ciências Humanas e Sociais em periódicos internacionais. Revista Brasileira de Pós-Graduação, 4 (8), 263-281. doi: $10.21713 / 2358-2332.2007 . v 4.133$

Santin, D. M., Vanz, S. A. S., \& Stumpf, I. R. C. (2016). Internacionalização da produção científica brasileira: políticas, estratégias e medidas de avaliação. Revista Brasileira de Pós-Graduação, 13(30), 81-100. doi: 10.21713/2358-2332.2016.v13.923 